\title{
Esophageal Perforation by a Bone: À Case Report
}

Houssam Belghali*, Abdelouhab El Marouni, Karam Aziz, Tarik Souiki, Imane Toughrai, Khalid Mazaz, Karim Ibn Majdoub Hassani

Visceral Surgery Service, Hassan II University Hospital, Faculty of Medicine and Pharmacy of Fez, Sidi Mohammed Ben Abdallah University, Fez, Morocco

DOI: $10.36347 /$ sasjs.2020.v06i02.014

| Received: 19.02.2020 | Accepted: 26.02.2020 | Published: 29.02.2020

*Corresponding author: Houssam Belghali

Abstract

Case Report

The ingestion of esophageal foreign bodies is a particularly frequent situation in clinical practice. It interests both the pediatric population (the majority of foreign bodies ingested are between 6 months and 6 years old) as the adult population as in our clinical case. The esophageal entrapment site is the main site for ingesting foreign bodies. The majority of them pass spontaneously. The interrogation makes it possible, in most cases, to make the diagnosis of foreign bodies of the esophagus and the difficult diagnostic situations are represented by the situations where the interrogation is impossible (child, adult mentally retarded, etc.). The clinic, more or less completed with imaging, nevertheless makes it possible to make the diagnosis in the majority of cases. The therapeutic urgency depends essentially on the patient's tolerance of the foreign body but also on the nature of this body (button cell, sharp foreign bodies, etc.). The therapeutic methods are multiple (abstention, drug treatment, flexible or rigid endoscopy, surgical treatment) and depend on local management skills but also on the nature of the foreign body. The presence but also the extraction of the foreign body is a source of complications whose existence must be known for optimal care.

Keywords: Esophagus; Diagnostic; Perforation; CT scan.

Copyright @ 2020: This is an open-access article distributed under the terms of the Creative Commons Attribution license which permits unrestricted use, distribution, and reproduction in any medium for non-commercial use (NonCommercial, or CC-BY-NC) provided the original author and source are credited.

\section{INTRODUCTION}

Esophageal perforation by ingestion of foreign body (EC) is rare, accounting for only 10 to $15 \%$ of esophageal perforation [1-3]. This perforation complicates approximately 3 to $6 \%$ of $\mathrm{CE}$ ingestion, which is known to occur more particularly in children, denture wearers, prisoners and psychiatric patients [47]. Esophageal perforations by $\mathrm{CE}$ affect the thoracic esophagus in 30 to $60 \%$ of cases and are associated with a mortality rate of 15 to $30 \%$ [3,8], most of the deaths being linked to septic complications. Before ingestion of $\mathrm{CE}$, the diagnosis of esophageal perforation is sometimes difficult. Perforation may occur in a delayed manner, secondary to mucosal necrosis or be diagnosed following an endoscopic extraction maneuver, during which edema of the mucosa may interfere with the diagnosis.

\section{CASE REPORT}

It is a 40-year-old man, with no notable pathological history, admitted to the emergency room for accidental ingestion of bones during a meal 07 day before. He complained of retro sternal chest pain with solids dysphagia. The clinical examination objectified a patient in shock with an HR at $120 \mathrm{bpm}, \mathrm{BP}$ at 10/7, with profuse sweating and cold extremities. The chest $\mathrm{x}$-ray and ASP were unremarkable.

The patient benefited 5 days before admission to our training from an attempted endoscopic extraction with failure. A Thorico-thoracic and abdominal scanner objectified the presence of a foreign body at the level of the thoracic esophagus with a pneumo mediastinum opposite (figure 1,2). Then the patient was operated (figure 3) after hemodynamic stability, where he benefited from a stripping, then transferred to resuscitation, the patient died after by a septic shock with a multi-organ failure not controlled by resuscitation measures. 


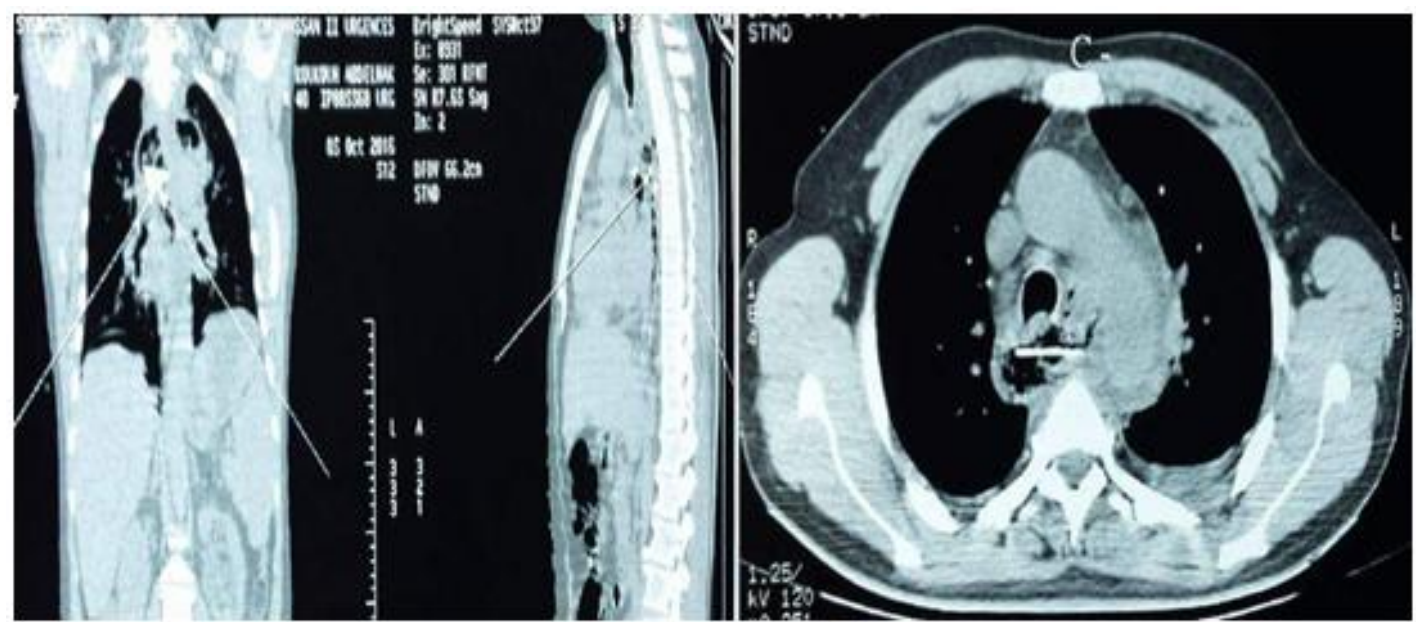

Fig-1, 2: The presence of a foreign body at the level of the thoracic esophagus.

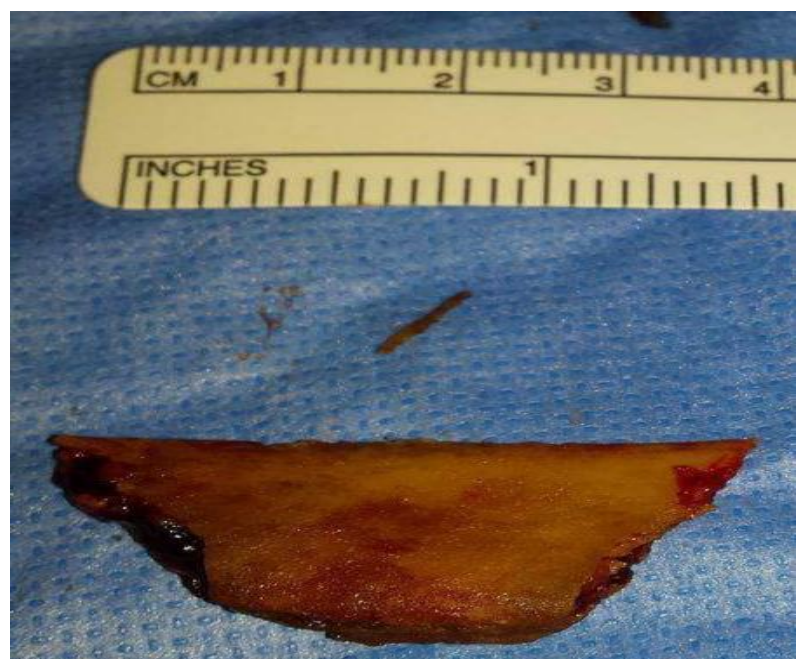

Fig-3: Bone that has perforated the esophagus

\section{DISCUSSION}

The diagnosis of perforations of the esophagus by $\mathrm{CE}$ is difficult, because it is done in a delayed manner in approximately a quarter of patients. In addition, the perforation can be linked directly to the $\mathrm{CE}$, to the extraction operations, or even to the two mechanisms. In our case, emergency endoscopy did not allow the CE to be extracted but it made it possible to diagnose the perforation.

The esophagus has three areas of narrowing conducive to the inclusion of CE: at its upper part, above the upper sphincter (cricopharyngeal muscle), at the level of the aortic arch and in the region of the cardia, above the sphincter lower esophagus [6, 9]. If the distribution of the etiologies of esophageal perforations has changed due to the development of diagnostic and interventional endoscopy, iatrogenic causes currently representing more than $50 \%$ of cases $[10,11]$, perforations secondary to ingestion of a $\mathrm{CE}$ represents 10 to $15 \%$ of these perforations $[1,3]$. These are most often bone or fishbone (the leading cause in Southeast Asia, but also in our series), coins, button cells, dentures or toys $[12,14]$. However, the perforation is secondary to extraction maneuvers in around $2 \%$ of CE ingestion $[4,5,7,15,16]$.

EC ingestion is observed in $80 \%$ of cases in children in the oral phase, usually six months to three years old $[17,18]$. In adults, CE ingestion is mainly observed in denture wearers, prisoners, psychotic or mentally retarded patients and alcoholics $[19,20]$.

The factors favoring EC impaction and esophageal perforation are the existence of a preexisting esophageal anomaly, the characteristics of the EC and the time taken for treatment. The esophageal anomalies favoring the occurrence of a perforation are neuromuscular disorders such as myasthenia gravis, motor diseases and extrinsic stenoses (for example linked to a tumor) or especially intrinsic (peptic, malformative, postoperative or neoplastic), perforation then making the upper pole of the stenosis $[2,4,15]$. However, certain series of esophageal ECs do not report any pre-existing esophageal abnormality [6]. The occurrence of a perforation is favored by the large size of the CE (thickness greater than $25 \mathrm{~mm}$ or a length greater than $6 \mathrm{~cm}$, for example, in the case of a pen, toothbrush, fork) [21], its sharp character (bone, bone) [22], its chemical activity (button cell) [23] and the duration of its impaction in the esophagus [7]. A sharp $\mathrm{CE}$, even a small one, can cause immediate perforation, possibly with a hemorrhagic complication, as soon as it is impacted in the esophagus [22]. Conversely, a CE with a foam edge or of a large size generally causes local necrosis of the esophageal wall with secondary perforation only if it remains impacted for several hours [17]. A special case is that of button cells, ingested as a rule by children, which generate esophageal lesions by combined electrical and mechanical effects and, exceptionally, are also toxic by the heavy metals they contain [23]. In the esophagus, mucosal damage can appear in three to four hours and a perforation in six hours [23]. Whatever the type of CE, the risk of perforation increases with time and the extraction of an impacted $\mathrm{CE}$ in the esophagus is therefore a therapeutic emergency $[6,7,17]$. Thus, in an endoscopic series, the 
incidence of esophageal complications was $11 \%$ in the event of impaction less than 24 hours, $52 \%$ in the event of impaction between 24 and 48 hours and $60 \%$ in the event of impaction greater than 48 hours [7].

Clinically, the picture is dominated by signs of EC impaction: dysphagia, hypersialorrhea and odynophagia linked to mucosal lesions which are sometimes very painful $[5,24]$ without being able to prejudge a perforation. The felt site of esophageal symptoms has only a weak localizing value [12]. A feeling of suffocation is possible when the EC is impacted in the cervical esophagus and causes compression of the air axis $[24,25]$. The classic clinical triad suggestive of esophageal perforation (pain, fever, emphysema) is therefore late and very inconsistent in CE perforations and should not be "expected" to evoke the diagnosis of perforation.

Rarely, the clinical diagnosis is much more difficult because the notion of ingestion of an EC is initially absent and the patient consults for upper digestive symptoms sometimes imprecise or a more serious picture.

Esophageal perforation formed with mediastinitis or purulent pleurisy [26]. The diagnosis is then based on the interrogation of the entourage, the chest X-ray (if the EC is radiopaque) and especially the chest CT.

The esophageal perforations by $\mathrm{CE}$ are of thoracic site in 40 to $60 \%$ of the cases, cervical in 30 to $40 \%$ of the cases and intra-abdominal in less than $10 \%$ of the cases [12, 13, 19]. Mortality of esophageal perforations complicated by mediastinitis and/or purulent pleurisy varies from 10 to $40 \%$ with an exponential increase after the sixth hour [3, 27, 28]. This highlights the importance of making the diagnosis of perforation as early as possible.

In our case, the chest x-ray was disappointing, in particular by failing to recognize an "initial" perforation. - both the diagnosis in $80 \%$ of cases by objectifying an extravasation of the contrast product to the mediastinal region and objectifying in some cases a preexisting anomaly (stenosis). But this examination has, in addition to its false negative rate, disadvantages: pulmonary edema in the event of inhalation of watersoluble, mediastinal fibrosis and discomfort with the subsequent interpretation of the images in the event of a barium leak in the mediastinum.

CT, without then with injection of contrast agent, is currently the best radiological examination for the diagnosis of esophageal perforation, especially if it is combined with the ingestion of water-soluble contrast agent [3]. Compared to chest radiography, CT can identify a limited pneumomediastinum (small mediastinal air bubbles around the vessels, bronchial tree, esophagus and heart), signs of "localized" mediastinitis (densification of the mediastinal fat with abnormal uptake of contrast, para-esophageal collection) and pleural effusions of low abundance or compartmentalized. In recent series, its sensitivity for the diagnosis of esophageal perforation is between 90 and $94 \%[3,29]$ and rises to $100 \%$ in the case of mediastinitis [30, 31].

\section{Endoscopy seems essential because it}

- Identifies non-radiopaque CEs (in particular food) and can observe a pre-existing (esophageal (stenosis) or associated esophageal abnormality (ulcers);

- Allows the extraction of $\mathrm{CE}$ in the majority of cases;

- Can visualize an esophageal perforation not seen in imaging. Thus, the sensitivity of endoscopy for the diagnosis of perforation is between 86 and $98 \%$ [3, 13, 33]. False negatives are partly linked to the visualization of mucosal damage (ulcerations, lacerations) wrongly considered as superficial or, to a significant parietal inflammation masking the perforation. Endoscopy is not contraindicated if there are CT signs of "limited" perforation with good clinical and biological tolerance, since medical treatment of the perforation can be reasonably attempted in this circumstance [34]. At the technical level, esophageal endoscopy for CE has long been performed using a rigid tube which, thanks to the operating channel and specific rigid instruments, allowed extraction of the $\mathrm{CE}$ in approximately $95 \%$ of cases [4-6]. However, flexible fiber endoscopy, despite a theoretical risk of diffusion of septic lesions linked to insufflation in the event of perforation, was gradually introduced in this indication due to:

- Its overall greater distribution and the appearance of specific material (gripping forceps, basket or balloon probe) facilitating the extraction of $\mathrm{CE}$ with an efficiency of about $95 \%$ similar to that obtained with the rigid esophagoscope[4,7,15,22]. Probably less significant risk of perforation than that (around 3\%) observed with the rigid tube [4].

The treatment of esophageal perforations is an emergency. Surgery is most often indicated. In 3 to $7 \%$ of $\mathrm{CE}$ ingestion, endoscopic extraction is not possible and surgery is necessary to extract the $\mathrm{CE}$ and suture the perforation [4-6]. The approach is then mainly guided by the location of the CE. When the perforation leads to severe septic complications (mediastinitis, purulent pleurisy), surgery is indicated to treat the perforation and its septic complications, the choice of the first route then also having to take into account the location of these complications [3] . A perforation of the cervical esophagus can be treated by simple suturing 
associated with drainage [3]. Reinforcement by a subhyoid muscle flap, or a large pectoral or sternocleidomastoid, may be associated if the perforation is difficult to suture [36]. For perforations of the thoracic esophagus, surgical treatment may be limited to mediastinal and/or pleural drainage by thoracotomy, or by thoracoscopy, after possible removal of the necrotic tissue next to the perforation if it is small, not identifiable due to the importance of inflammatory phenomena, or if the imagery suggests that it is "blocked". "Classic" surgical treatment combines economic trimming of the edges of the perforation, the suture of the latter possibly reinforced by a muscular or intercostal flap, debridement and wide drainage of the mediastinum and pleural cavities [37], possibly supplemented by the establishment of a feeding gastrostomy or jejunostomy. Exceptionally, if the edges of the wound are not easily sutured, the suture can be performed on a Kehr T-tube creating a directed fistulization [38], or can be associated with exclusion by transmural stapling at the level of the esophagus cervical and abdominal [39, 40], associated with cervical esophagostomy. These heavier gestures than the simple suture, and intended to treat septic phenomena more radically, like stripping in the case of our patient, expose to a later or more random per os refeeding, possibly after a second surgical time.

Medical treatment, always combined with surgical treatment, includes effective antibiotic therapy against germs in the ENT and upper digestive tract, management of the respiratory impact of the perforation ranging from simple oxygen therapy to assisted ventilation and nutritional support by diet. Parenteral or enteral (gastrostomy, jejunostomy or weighted nasogastric tube). Exclusive medical treatment may be attempted if the perforation is punctate, if there is no regional infection or visceral failure, or if the perforation is diagnosed late with a "spontaneous" course suggesting that it is compartmentalized, or if it occurs in patients at high surgical risk, provided that the esophagus is free of obstructive or tumor pathology [34, $41,43]$. Esophageal clouding with water-soluble is therefore necessary to retain the indication for this treatment. A compartmentalized leak of the contrast medium or signs of localized perforation in CT allow this non-surgical treatment to be attempted [34]. Based on these selection criteria, non-surgical treatment is effective in $80 \%$ of patients, the remaining $20 \%$ having to be finally operated due to complications occurring within 24 hours of initiation of treatment [42]. In patient no 6 , this treatment was followed by the creation of a mediastinal abscess treated by surgical drainage, the perforation which was probably small having developed favorably. The duration of exclusive medical treatment is seven days with an opacification of the esophagus in the process before any oral refeeding [44]. This medical treatment can currently be associated with an endoscopic treatment, consisting in the installation of a covered and removable esophageal endoprosthesis, "bridging" the perforation glued using biological glue $[45,46]$, or the closing of the perforation by clips if it is less than $1.5 \mathrm{~cm}$ in size and with sharp edges [25, 47]. Exclusive non-surgical treatment seems relatively easy to indicate in children, in particular in perforations of the cervical esophagus (60 to $80 \%$ of favorable results) $[48,49]$. For thoracic perforations, the exclusive nonsurgical treatment seems reasonable only in the event of a perforation diagnosed early. Thus, in a study of 62 patients, survival after exclusive medical treatment was $87 \%$ and $70 \%$ respectively in the case of diagnostic delays of less than and more than 24 hours [50].

\section{CONCLUSION}

Diagnosis of perforation of the esophagus by $\mathrm{CE}$ is difficult, as it is done in a delayed fashion in about a quarter of patients. In addition, the perforation can be linked directly to the CE or to the extraction operations. CT and endoscopy are essential for the diagnosis and treatment of esophageal perforations by $\mathrm{CE}$. The place of surgical treatment remains important.

\section{REFERENCES}

1. Cheynel N, Arnal E, Peschaud F, Rat P, Bernard A, Favre JP. Perforation et rupture de l'œsophage : prise en charge et pro- nostic. Ann Chir. 2003;128:163-6.

2. Michel L, Collard JM. Perforation, Boerhaave's syndrome, and Mallory-Weiss syndrome. In: Oxford textbook of surgery. Oxford University Press. 1994: 868-73.

3. Gayet B, Perniceni Th, Boudet MJ. Résultats de l'enquête de l'AFC : analyse multivariée. In: Célérier M, Gayet B, editors. Les traumatismes de l'œsophage. Paris: Arnette Blackwell. 1995: 49110.

4. Gmeiner D, von Rahden BHA, Meco C, Hutter J, Oberascher G, Stein HJ. Flexible versus rigid endoscopy for treatment of foreign body impaction in the esophagus. Surg Endosc. 2007;21:2026-9.

5. Athanassiadi K, Gerazounis M, Metaxas E, Kalantzi N. Manage- ment of esophageal foreign bodies: a retrospective review of 400 cases. Eur J Cardiothorac Surg. 2002;21:653-6.

6. Weissberg D, Refaely Y. Foreign bodies in the esophagus. Ann Thorac Surg. 2007;84:1854-7.

7. Chaves DM, Ishioka S, Félix VN, Sakai P, GamaRodrigues JJ. Removal of a foreign body from the upper gastrointestinal tract with a flexible endoscope: a prospective study. Endoscopy. 2004;36:887-92.

8. Attar S, Hankins JR, Sutter CM, Coughlin TR, Sequeira A, McLaughlin JS. Esophageal perforation, a therapeutic chal- lenge. Ann Thorac Surg. 1990;50:45-51.

9. Jougon J, Delcambre F, MacBride T, Minniti A, Velly JF. Mortality from iatrogenic esophageal 
perforations is high: experience of 54 treated cases. Ann Chir. 2002;127:26-31.

10. Giudicelli R. Esophageal perforations. Results of a national sur- vey. Ann Chir 1992;46:183-7.

11. Endara SA, Serrano AJ, Sandoval BA, Davalos GA. Esophageal perforation during gastric bypass: delayed diagnosis and mana- gement. Obes Surg. 2007;17:986-8.

12. Ashraf O. Foreign body in the esophagus: a review. Sao Paulo Med J. 2006;124:346-9.

13. Benito Navarro JR, Del Cuvillo Bernal A, Porras Alonso E. Esophagal foreign bodies. Our 10years of experience. Acta Otorrinolaringol Esp. 2003;54:281-5.

14. Smith MT, Wong RK. Foreign bodies. Gastrointest Endosc Clin N Am. 2007; 17:361-82.

15. Mosca S, Manes G, Martino R. Endoscopic management of foreign bodies in the upper gastrointestinal tract: report on a series of 414 adult patients. Endoscopy. 2001;33:692 - 6.

16. Lam HC, Woo JK, van Hasselt CA. Management of ingested foreign bodies: a retrospective review of 5,240 patients. J Laryngol Otol. 2001;115:9547.

17. Yal,cin S, Karnak I, Ciftci AO, Senocak ME, Tanyel FC, Büyükpamuk,cu N. Foreign bodies ingestion in children: an analysis of pediatric surgical practice. Pediatr Surg Int. 2007;23:75561.

18. Kay M, Wyllie R. Pediatric foreign bodies and their manage- ment. Curr Gastroenterol Rep. 2005;7:212-8.

19. Brady PG. Esophagal foreign bodies. Gastroenterol Clin North Am. 1991;20:691-701.

20. Abdullah BJ, Teong LK, Mahadevan J, Jalaludin A. Dental prothesis ingested and impacted in the esophagus and orola- ryngopharynx. J Otolaryngol. 1998;27:190- 4 .

21. Tokar B, Cevik AA, Ilhan H. Ingested gastrointestinal foreign bodies: predisposing factors for complications in children having surgical or endoscopic removal. Pediatr Surg Int. 2007;23:135-9.

22. Jeen YT, Chun HJ, Song CW. Endoscopic removal of sharp foreign bodies impacted in the esophagus. Endoscopy. 2001;33:518-22.

23. Laugel V, Beladdale J, Escande B, Simeoni U. L'ingestion acci- dentelle de pile-bouton. Arch Pediatr. 1999;6:1231-5.

24. Little DC, Shah SR, St Peter SD. Esophageal foreign bodies in the pediatric population: our first 500 cases. J Pediatr Surg. 2006;41:914—8.

25. Wu JT, Mattox KL, Wall MJ. Esophageal perforations: new perspectives and treatment paradigms. J Trauma 2007;63:1173-84.

26. Michel L, Grillo HC, Malt RA. Esophageal perforation. Ann Tho- rac Surg. 1982; 33:203-10.

27. Michel L, Grillo HC, Malt RA. Operative and nonoperative management of esophageal perforations. Ann Surg. 1981;194: 57-63.
28. Salo JA, Isolauri JO, Heikkilä LJ. Management of delayed esophageal perforation with mediastinal sepsis. Eso- phagectomy or primary repair? J Thorac Cardiovasc Surg. 1993;106:1088 — 91.

29. De Lutio di Castelguidone E, Pinto A, Merola S, Stavolo C, Romano L. Role of spiral and multislice computed tomo- graphy in the evaluation of traumatic and spontaneous esophagal perforation. Our experience. Radiol Med. 2005;109: 252—9.

30. Reghini CA, Tea BZ, Reyt E, Chahine KA. Cervical cellulitis and mediastinitis following esophageal perforation. World J Gas- troenterol. 2008;14:1450-2.

31. Exarhos DN, Malagari K, Tsatalou EG. Acute mediasti- nis: spectrum of computed tomography findings. Eur Radiol. 2005;15:1569-74.

32. Kotsis L, Kostic S, Zubovits K. Multimodality treatment of eso- phageal disruptions. Chest. 1997;112:1304-9.

33. Uba AT, Sowande AO, Amusa YB. Management of esophageal foreign bodies in children. East Afr Med J 2002;79:334-8.

34. Naidoo RR, Reddi AA. Chronic retained foreign bodies in the esophagus. Ann Thorac Surg. 2004;77:218-20.

35. American Society for Gastrointestinal Endoscopy. Guideline for the management of ingested foreign bodies. Gostrointestinal Endoscopy. 2002;55:8026.

36. Rosiere A, Mulier S, Khoury A, Michel L. Management of esopha- geal perforation after delayed diagnosis. The merit of tissue flap reinforcement. Acta Chir Belg. 2003;103:497501.

37. Davies B, Black E, Vaughan R. Thoracoscopic drainage of and foreign body removal from a posterior mediastinal abscess. Eur J Cardiothorac Surg. 2004;25:897-8.

38. Sakamoto $\mathrm{Y}$, Tanaka N, Furuya $\mathrm{T}$, Ueno $\mathrm{T}$, Okamoto H, Nagai M. Surgical management of late esophageal perforation. J Thorac Cardiovasc Surg. 1997;45:269-72.

39. Gupta NM. Emergency transhiatal esophagectomy for instru- mental perforation of an obstructed thoracic esophagus. Br J Surg. 1996;83:1007—9.

40. Vidrequin A, Mangin P, Beck M, Bresler L, Boissel P, Grosdidier J. Esophageal exclusion using resorbable staples: application in one-stage conservative treatment in Boerhaave's syndrome. Ann Chir. 1988;42:267-70.

41. Chang MY, Chang ML, Wu CT. Esophageal perforation caused by fish vertebra ingestion in a seven-month-old infant deman- ded surgical intervention: a case report. World Gastroenterol. 2006;12:7213-5.

42. Shaffer HA, Valenzuela G, Mittal RK. Esophageal perforation: reassessment of the criteria for choosing medical or surgical therapy. Arch Intern Med. 1992;152:757—61. 
43. Altorjay A, Kiss J, Voros A, Bohak A. Nonoperative mana- gement of esophageal perforations. Is it justified? Ann Surg. 1997;225:415-21.

44. Weiland ST, Schurr MJ. Conservative management of ingested foreign bodies. J Gastrointest Surg 2002;6:496-500.

45. Schubert D, Scheidbach H, Kuhn R. Endoscopic treatment of thoracic esophageal anastomotic leaks by using silicone- covered, self-expanding polyester stents. Gastrointest Endosc. 2005; 61:891-6.

46. Freeman RK, Van Woerkom JM, Ascioti AJ. Esophageal stent placement for the treatment of iatrogenic intrathoracic eso- phageal perforation. Ann Thorac Surg. 2007;83:2003-8.

47. Sung HY, Kim JI, Cheung Y. Successful endoscopic hemoclipping of an esophageal perforation. Dis Esophagus. 2007;20:449—52.

48. Tilanus HW, Bossuyt P, Schattenkerk ME, Obertop H. Treatment of esophageal perforation: a multivariate analysis. Br J Surg. 1991;78:582-5.

49. Friedberg JS, Deeb ME. Esophageal perforation. In: Mastery of surgery. Philadelphia: LippincottWilliams and Wilkins. 2001. 843-52.

50. Kiernan PD, Sheridan MJ, Elster E, Rhee J, Collazo L. Thoracic esophageal perforations. South Med J. 2003;96:58-63. 